\title{
Article
}

\section{Target versus ball focused aiming when golf putting: What has been done and what has been missed}

Moffat, D., Collins, D., and Carson, H.J.

Available at http://clok.uclan.ac.uk/18678/

Moffat, D., Collins, D., ORCID: 0000-0002-7601-0454 and Carson, H.J. ORCID: 0000-0002-3785-606X (2017) Target versus ball focused aiming when golf putting: What has been done and what has been missed. International Journal of Golf Science, 6 (1). pp. 35-55. ISSN 2168-7595

It is advisable to refer to the publisher's version if you intend to cite from the work. http://dx.doi.org/10.1123/ijgs.2017-0002

For more information about UCLan's research in this area go to http://www.uclan.ac.uk/researchgroups/ and search for < name of research Group>.

For information about Research generally at UCLan please go to http://www.uclan.ac.uk/research/

All outputs in CLoK are protected by Intellectual Property Rights law, including Copyright law. Copyright, IPR and Moral Rights for the works on this site are retained by the individual authors and/or other copyright owners. Terms and conditions for use of this material are defined in the policies page.

\section{CLoK}

Central Lancashire online Knowledge www.clok.uclan.ac.uk

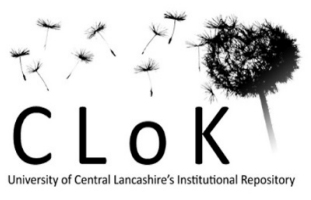


2

3 Target versus Ball Focused Aiming when Golf Putting: What has been done and what has 4 been missed

6

112 Institute for Coaching and Performance, University of Central Lancashire, Preston, UK 12

$18 *$ Correspondence concerning this paper should be addressed to David Moffat, Myerscough

19 College, St Michael's Road, Bilsborrow, Preston, PR3 0RY, United Kingdom. E-mail:

20 dmoffat@myerscough.ac.uk 
Abstract

22 As the prevalence of target focussed aiming in golf putting increases amongst professionals

23 and amateurs alike, it is important to understand its operation if the synergy between research

24 and practice is to be optimised. Therefore, the current paper's aims were firstly to review and

25 critique existing empirical literature. Although our observations of these studies were

26 informative, however, we identified a number of key methodological inconsistencies and

27 omissions, which limits our understanding as a complete evidence-base across studies.

28 Consequently and secondly, we provide insight into possible mechanisms for how target

29 focussed aiming might work with corresponding measures for investigating these suggestions.

30 Finally, we propose a number of methodological considerations that need to be addressed by

31 future research. It is hoped this research will inform future practice when coaching the skill

32 of putting.

33

34

Keywords: coaching, electroencephalography, gaze behaviour, intention/attention,

35 visual aiming 
Target versus Ball Focused Aiming when Golf Putting: What has been done and what has been missed

For closed and self-paced skills, technique plays an important role. As such, it is unsurprising that much research and practical instruction is dedicated to understanding how athletes move (e.g., Bartlett, 2007; Blazevich, 2012). One domain characterised by this focus is golf (e.g., Keogh \& Hume, 2012; Meister et al., 2011), where differences between techniques are widely compared and evaluated amongst coaches (McHardy, Pollard \& Bayley, 2006; Rodgers, Reade \& Hall, 2007; Smith et al., 2015). In contrast, however, less critical attention has been applied to the relationship between perceptual processes and the effective selection, then execution, of an appropriate motor strategy (e.g., Hatfield, Haufler, Hung \& Spalding, 2004; Nieuwenhuys \& Oudejans, 2012; Schmidt, 1975). This is unfortunate since there is an obvious demand on the interaction between these processes during, for example, the task of putting. In this particular context, golfers must be able to accurately identify and utilise several factors, including target location and distance, surface topography and speed, in determining swing parameters such as aim direction and swing velocity. Accordingly, it is interesting that recent performances of some professional golfers (e.g., Major champions Jordan Speith and Louis Oosthuizen) have demonstrated much success in using a technique that challenges the perceived wisdom to "keep your eyes over the ball during execution" (hereafter termed ball focused aiming; BFA). Rather, these golfers putt whilst orienting their head, neck and visual field toward the target location during execution (hereafter termed target focused aiming: TFA, Figure 1). Such observations of sport (cf. Collins \& Kamin, 2012) present challenge to fundamental understanding that is often developed through sport (e.g., Moore, Vine, Cooke, Ring \& Wilson, 2012; Steinberg, Frehlich \& Tennant, 1995; Vickers, 2012). Of course, as practitioners we are ultimately concerned with developing understanding for sport; in short, translational research. Crucially, decision making is understood to be an important part of coaching practice, which this paper 
aims to fundamentally inform (Abraham \& Collins, 2011); both procedural ("how to do it") and declarative ("what needs to be done and why"), so an understanding of both parameters is important within this process. Therefore, in an attempt to support such decision making processes, the purpose of this paper is threefold. Firstly, we review and critique existing empirical literature on TFA; secondly, we offer potential perspectives to explain how TFA works and appropriate measures that could be used to illuminate such understanding, and; thirdly, we propose recommendations for future research to address aiming strategies in golf putting.

\section{Existing Research: What has been done}

Reflecting the aforementioned scarcity of research on TFA in golf, this section reviews the existing empirical evidence-base that has attempted to address this process. As a brief overview of effects, it is important to recognise that most studies have examined the impact of TFA on performance, with only MacKenzie, Foley and Adamczyk (2011) reporting process measures of putter head kinematics. Overall, findings are mixed. Some studies have shown performance improvement when using TFA (e.g., Alpenfels, Christina \& Heath, 2008), others a disadvantage (e.g., Gonzalez, Kegel, Ishikura \& Lee, 2012; Wannebo \& Reeve, 1984) and others have shown no difference at all compared to BFA (e.g., Aksamit \& Husak, 1983; Bowen, 1968; Cockerill, 1978; Gott \& McGown, 1988). For process measures relating to putter head kinematics, the main difference appears in the level of consistency between strokes, with TFA affording lower variability between trials for putter speed at impact. As yet, however, kinematics of the golfer's body is unreported within the literature (see Table 1 for a summary of the studies in greater detail).

Notably, for any programme of investigation to be coherent, it is crucial for experimental features to be resolutely combined with controlled variations from one study to the next (cf. Goginsky \& Collins, 1996) as understanding of the phenomenon in question develops. However, such a chain between studies appears to be lacking on this topic, as 
evidenced by several inconsistencies and omissions. Accordingly, these are explored in order to provide a clearer overall picture of what has been done so far. It is also worth acknowledging the timescales over which these studies have been conducted; the earliest of eight studies being published in 1968. With this in mind, it is not our intention to be unfairly critical of this research (considering the obvious advances in technology plus the increased sociocultural value placed on applied research etc. over this period) but rather, to use the review as a process for identifying elements that would need to be addressed if we are to move forward in the present day, presenting a clear chain of methodological progression to feed into coaching practice.

****Insert Table near here $* * * *$

\section{Inconsistencies within Existing Research}

Participants. Despite much research into expert-novice differences with respect to golf putting in general (e.g., Hasegawa, Fujii, Miura \& Yamamoto, 2017; Taylor \& Shaw, 2002), there has been a lack of comparison between these skill levels when employing the different putting methods (i.e., BFA vs. TFA). Studies within Table 1 were mostly conducted on novice golfers with no golfing experience; largely learning studies with little transferability to experienced and/or elite-level golfers. Typically, participants were university students classified as beginner golfers (Aksamit \& Husak, 1983; Bowen, 1968; Cockerill, 1978; Gott \& McGown, 1988; Wannebo \& Reeve, 1984). Only three studies (Alpenfels et al., 2008; MacKenzie et al., 2011; Wannebo \& Reeve, 1984) used active golfers (handicaps 8-36) and only one (Cockerill, 1978) used participants described as "elite amateur golfers" (handicap < 6; p. 379). Notably, Wannebo and Reeve (1984) and Gonzalez et al. (2012) distinguish their participant groups by years of 'experience' to infer skill level that, we suggest, is not the same thing and, therefore, potentially misleading (see Carson \& Collins, 
2016a). Handicap is a measure for grading amateur golfers but genuine novices will, by definition, not have one- beginner golfers typically have insufficient experience to achieve an accurate handicap. Moreover, handicap rates golfers' overall performance rather than just their putting skill (Robertson, Gupta, Kremer \& Burnett, 2015).

An important lack of interrelation between handicap and putting skill is illustrated by professional golf tour rankings, whereby overall and putting rankings are not always the same (e.g., the 2015 European Tour Order of Merit winner was ranked 18 on putts per green in regulation and the number 1 ranked golfer on putts per green in regulation was ranked 171 overall). However, the handicap systems (USGA and R\&A) are the globally recognised measure of an amateur golfer's skill level and should be used (when available) to inform the reader. Whilst it may be accepted that the 'low skilled' group described by Wannebo and Reeve (1984) and Gonzalez et al. (2012) might not have had an official handicap to report, failure of the authors to omit the 'highly skilled' groups' handicap level is a factor that should have been addressed to inform future research.

Returning to the overall picture, there are several potential confounds to the results obtained. Since the majority of participants tested were nongolfers, their performance could have depended on a number of factors, including: confidence levels, motivation to engage in the task, consistency (or lack thereof) of putting stroke, green reading ability and ability to align the club with the ball. Another possible limitation of the studies was participants' limited understanding toward the vision strategy of elite golfers. To be clear, the visual strategy of elite golfers includes all gaze behaviours prior to the final fixation on the ball, such as pursuits and saccades where both the duration and location of these gaze behaviours have been suggested to be important for putting performance (Vickers, 2012). Therefore, studies that used non-elite golfers in Table 1 may not have undertaken a robust test of comparisons between the two methods.

Furthermore, the papers cited gave no mention of participants' ocular dominance prior 
to testing. Ocular dominance is an essential visual component of aligning the ball with the target and the club with the ball (Farnsworth, 1997). According to Steinberg et al. (1995), ocular dominance impacts on putting accuracy. Their analysis indicated a significant interaction for dextrality and the relative position of the eyes during putting. Pure dextral (defined as symmetry in eye and hand) golfers demonstrated significantly less absolute error $(10.65 \mathrm{~cm} \pm 2.1$ vs. $8.98 \mathrm{~cm} \pm 2.5)$ and less variable error $(11.76 \mathrm{~cm} \pm 1.85$ vs. $9.99 \mathrm{~cm} \pm$ 2.44 ) in their putting performance from a distance of $3.66 \mathrm{~m}$ when they positioned their eyes midway between the ball and their feet compared to when they positioned their eyes directly over the ball. In practice, testing gaze behaviour, vision and green reading (determining the target line and distance) requires the use of stereopsis (the perception of depth produced by the reception in the brain of visual stimuli from both eyes), which is, in turn, affected by visual acuity. Notably, no studies within Table 1 referred to participants being visually examined for normal or corrected vision (e.g., a need for glasses or contact lenses) during the trials. Once again, this circumstance is not ideal for generating a 'state of the nation' consensus on the topic.

Equipment. The impact of golf club custom fitting has been shown to significantly improve club head speed, speed variability and tempo amongst novice golfers (Bertram \& Guadagnoli, 2008), as well as being common practice nowadays within the applied setting. Due to the optimum putter loft varying as a function of the friction coefficient on any given putting green (i.e., in major part resulting from the grass length), putter length and lie angle are the two most prioritised aspects when conducting a putter fitting (Swash, 2016). The golfer's height and eye dominance (see previous section) are both important in determining these two outcomes. However, Aksamit and Husak (1983), Bowen (1968) and Cockerill (1978) all used standardised or centre shafted putters. In contrast, Wannebo and Reeve (1984) gave participants the option of using their own putter or, again, a putter supplied (i.e., standardised), while MacKenzie et al. (2011) used a Nike Unitized Retro putter (35” length) 
and Gonzalez et al. (2012) used a Ping Anser putter (length was not reported) across all participants. These inconsistencies make it difficult, if not impossible, to replicate or extend the experimental design. Furthermore, we must be sceptical about using standardised putters since evidence suggests that use of a 'distorted' putter leads to suboptimal performance for both novices and experts (Experiment 2; Beilock \& Carr, 2001). While Beilock and Carr used a purposefully designed 'funny putter', we (the first author being a highly skilled amateur and third author a PGA Professional golf coach) recommend that similar discomfort can also occur when a putter merely feels or looks 'unfamiliar' (the latter notably not an issue during TFA), with length of shaft being a major contributor to this by altering the posture and degree of flexion at the elbows.

The type of golf balls used in the research was also inconsistent. For example, Wannebo and Reeve (1984) used nonconforming (for competitive play) driving range balls that would have different features such as compression (determined by the hardness of the core) and spin rate. These differences can be substantial, producing different dynamics to that of a conforming ball and could therefore have impacted on the results, or at the very least our ability to make accurate comparisons between different studies (Monk, Davis, Strangwood \& Otto, 2004). Moreover, one must also consider the impact of unfamiliarity toward this type of golf ball for putting; it is more usual for golfers to execute full shots with a driving range ball on a driving range, or course. A Dunlop 65 ball was used in the Cockerill (1978) study which is a smaller sized ball ( $4.11 \mathrm{~cm}$ diameter) compared to that of the universally (both US and R\&A rules) conforming ball since 1990 of $4.26 \mathrm{~cm}$ diameter. MacKenzie et al. (2011) used an approved R\&A/USGA conforming ball (Callaway Tour i) and Gonzalez et al. (2012) also used a conforming ball (Titleist NXT). Unfortunately, there was no record of ball type used in Alpenfels et al. (2008). However, R. Christina (personal communication, June 20, 2016) has since confirmed the use of a conforming ball (Titleist Pro V1). As a minimum, we must be cautious about data from studies using nonconforming equipment (according to modern 
regulations) if they are to inform practice under different modern task constraints.

Nature of the dependent variable. In determining the effect of different experimental manipulations it is important to know the sensitivity of measures employed. For golfers and their coaches it is meaningful to know whether new training practices have been able to show an increase in putts holed or simply whether putts are missed to a lesser extent. Within the medical domain this may be similar to knowing whether a treatment merely slows down the progression of a disease or is a genuine option for cure. Certainly, and again, reflecting our point that inconsistency between studies makes it difficult to ascertain a consensus about the effect of TFA versus BFA, some studies have measured the number of putts holed (e.g., Cockerill, 1978; MacKenzie et al., 2011) and others the actual final distance from the ball to hole after each trial (e.g., Aksamit \& Husak, 1983). However, even when the final distance to the hole is measured, Fischman (2015) stresses that exact measurements can be of varied usefulness. Specifically, when referring to the use of concentric circles around a target (as is commonly used for aiming studies) with assigned points for landing an object within each circular 'zone', Fischman points out that despite the same score being possible on two or more trials, the location is often ignored with respect to understanding performance differences. As such, future studies must be careful even when reporting on simple measures of displacement.

Experience with employing TFA. Considering that experts are known to improve their skill, even if by small amounts, following increased experience (Crossman, 1959), it is important to note that TFA studies provide a varied (and potentially insufficient) amount of time for participants to practice this new putting method. Indeed, this is particularly so for studies using active golfers who, by comparison, would have amasses many more hours of practice with the BFA method. For example, MacKenzie et al. (2011) conducted pre and posttests with a 4 week practice period in between, Gott and McGown (1988) used an alternative practice-test schedule for a period of 8 weeks and Alpenfels et al. (2008) collected 
all data within a single session. Therefore, it is difficult to compare effects across studies conducted. In practice coaching is, ideally (although we acknowledge that some athletecoach relationships serve more specific and short-term purposes), operationalised longitudinally. Golfers are often permitted weeks, sometimes months (Carson \& Collins, 2015), to work on developing their skills. Accordingly, it would be most revealing to demonstrate effects over greater (but more frequent) timescales as a depiction of players' reality, for both novices and active golfers.

Environmental context. Finally, to be able to evaluate research findings for use in golf (cf. Collins \& Kamin, 2012), it is important that the environmental context holds sufficient ecological validity. Unfortunately, several of the studies to date were completed within an indoor laboratory setting (see Drane, Duffy, Fournier, Sherwood \& Breed, 2014, for more on artificial turf-ball interaction conditions) rather than on the ground conditions experienced on an actual golf course (Bowen, 1968; Gonzalez et al., 2012; Gott \& McGown, 1988; MacKenzie et al., 2011). We are not suggesting laboratory experiments are not useful (Berkowitz \& Donnerstein, 1982; Christina, 1987), merely highlighting their fundamental drive to test causal hypotheses.

Moreover, the trials generally consisted of straight or flat putting tasks (Alpenfels et al., 2008; Cockerill, 1978; Gott \& McGown, 1988; MacKenzie et al., 2011; Wannebo \& Reeve, 1984) with the distance and direction of tasks insufficiently varied to truly represent golf putting. For instance, Cockerill (1978) tested putts of only 1 and $2 \mathrm{~m}$ in length whereas Alpenfels et al. (2008) covered a range of both short (3ft-8ft) and long (20ft-40ft) distances. Typically, putts will vary in length and have a slope and/or break to them, with a straight or flat putt being a rarity on a natural putting green. Indeed, the recently proposed mesh theory by Christensen, Sutton and McIlwain (2016) explains a differential level of control applied by performers depending on the task demands. When the task is very straightforward, and the performer has amassed plenty of experience at it, an automatic, effortless, fluid and 
attentionally undemanding state is possible for successful execution. However, Christensen et al. put the case forward that these do not characterise most sporting situations (see also Toner \& Moran, 2015), despite experimental research depicting them as so. In such instances, performers may successfully complete the task by consciously applying attentional resources to key elements of their strategy. Carson and Collins (2016a) extended this work by explaining that it depends on what and how this attention is allocated that determines whether self-foci are either positive or negative toward the task (cf. Masters, 1992; Wulf, 2013). Consequently, a frequent lack of ecological validity raises doubt over the confidence with which we may say that TFA $i$ s better than BFA or indeed a viable alternative that should be introduced within golf coaching. Of course, fundamental research can offer many benefits (cf. Christina, 1987); however, more ecologically valid environments and tasks must be used if we are to further our understanding of the processes involved in, and effectiveness of, TFA in the real-world. Considering the limited number of studies conducted on TFA, we suggest that these inconsistencies further reduce the power of conclusions made regarding its effect. In short, at present we cannot know for sure what benefits, if any, exist.

\section{Omissions within Current Research}

When studies are designed and executed relative to previous literature, it creates a well-constructed expansion of knowledge. Although the strengths of the previous research do outweigh the criticisms, we will now highlight several important omissions.

Examination of robustness under high-anxiety conditions. With the exception of Gott and McGown (1988), who provided weekly rewards for consistent effort to participants for holing the most putts in practice, no other studies included a competitive and/or pressured situation into their experimental designs. In fact, it is questionable as to whether the rewards provided by Gott and McGown even promoted high levels of anxiety over such timescales.

Certainly no data were reported to confirm that this was the case, nor do they state promoting high anxiety as their intention. This is an important omission if we are to translate empirical 
findings into effective coaching practice and performance. High-anxiety conditions are an almost inevitable feature of representative competitive sport (see Christensen et al., 2016) that coaches and athletes should address within their training, although this appears to be underaddressed as a proactive process in some golfing situations (Carson, Collins \& MacNamara, 2013).

We are not saying that other golf skills do not require security under the most testing of conditions; they do. However, to illustrate such a point within the context of our paper's target focus, consider the cases of Dustin Johnston (who 3 putted from $12 \mathrm{ft} .4$ in. on the last hole, costing him the 2015 US Open) and Doug Sanders (who missed a $3 \mathrm{ft}$. putt on the last hole, losing him the 1970 Open Championship). These are in contrast to Mike Weir's and Jordan Speith's successes, both winning Major championships by remarkable putting. Furthermore, testing a skill's robustness under realistic sources of pressure/transfer is coherent with applied models of technical change (the Five-A Model; Carson \& Collins, 2011), a crucial factor for coaches and sport psychologists (Carson \& Collins, 2016b) working with golfers already experienced in using the BFA method but attempting to modify their putting to a TFA approach.

Reflecting an interaction of possible mechanisms, current understanding of the anxiety-performance relationship explains a breadth of cognitive, physiological and selfregulatory (Cheng, Hardy \& Markland, 2009) but also motoric (Carson \& Collins, 2016a) dimensions acting across perceptual, skill selection and execution phases of the performance (Nieuwenhuys \& Oudejans, 2012). As such, we suggest that golfers require an optimum, although individually specific (e.g., Bortoli, Bertollo, Hanin \& Robazza, 2012), blend of these dimensional functions across phases of performance and development. Further investigation of TFA with the inclusion of high-anxiety testing may assist in building our declarative understanding of, for example, how such factors interact, their relative importance, who should be using TFA and, crucially for coach decision making, why. In practical terms, 
monitoring of key process markers has the potential to improve the provision of quality feedback (Collins, Carson \& Cruickshank, 2015) and subsequent training (including that of mental skills) to promote better competitive performance.

Varying green topography. A common demand on golfers within the task of putting is to, despite the closed environmental nature, correctly read the different slopes and pace of putting surfaces. In a study by Wilson and Pearcy (2009), visuomotor control was assessed for flat and breaking putts. Unsurprisingly, performance data indicated that golfers (six university golf team members, no reporting of their skill level) found severely sloped putts more difficult than either the moderate or flat putts. Slopes and undulations are utilised by golf course architects to increase the difficultly level of putting. Unpredictable and irregular topography requires the golfer to accurately perceive and determine the proposed path the ball will follow towards the hole. Golfers must calculate the degree of break, the speed of the green and the force required to project the ball the correct distance to the hole. Unfortunately only Bowen (1968) tested putts of different slope. Experimental testing of TFA on a variety of putting surfaces may therefore provide a better idea about its effectiveness when compared to BFA.

\section{Investigating TFA: How it Might Work and be Assessed}

Considering the nature of putting, it is most appropriate to present possible explanations that are grounded within motor control literature. Notably, and recognising the complexity of processes involved across multiple timescales (see Newell, Liu \& MayerKress, 2001), we limit possible explanations here to situations in which TFA is a learnt and well established (cf. Carson \& Collins, 2016a) putting method. However, we explore multiple levels of explanation (Rose, 1997) within this diverse domain (e.g., Gallicchio, Cooke \& Ring, 2017; Keogh \& Hume, 2012; Vickers, 2016) presenting three possible (of possibly many) explanations for how TFA might work, offering visual, nonvisual/internal focus and physio-mechanical perspectives. Notably, these mechanisms may not operate in 
pure isolation, nor might this balance be equivalent across individuals. Considering the early stage nature of research into TFA however, we feel it is most beneficial to present the ideas as separate for optimal overall understanding.

\section{Visual Explanation}

Perhaps the most intuitive advantage for using TFA comes from benefits in visual system functioning while putting. Indeed, many studies have suggested that there is a relationship between golfers' eye gaze patterns and performance levels; the most common variable of interest being the quiet eye (QE), or final fixation (Vickers, 2016). For clarity, the QE is defined as the final fixation toward a specific location or object in the task space within $3^{\circ}$ of visual angle for a minimum of $100 \mathrm{~ms}$. Onset occurs prior to a critical movement in the task and the offset occurs when the gaze deviates off the object or location by more than $3^{\circ}$ of visual angle for a minimum of $100 \mathrm{~ms}$. According to several studies a longer demonstration of QE is indicative of expertise, especially for closed and self-paced skill aiming tasks (e.g., Mann, Williams, Ward \& Janelle, 2007; Vickers, 2012).

Furthermore, Lee, Ishikura, Kegel, Gonzalez and Passmore (2008) suggest that a more difficult egocentric (versus the novice preferred allocentric) head-putter coordination pattern may have predominated due to enhanced information gained from the visual system. In short, this strategy supports an attentional explanation, utilising retinal feedback to extract superior information from the environment. Extrapolating this perspective, TFA may, therefore, provide pertinent environmental information to the golfer for longer durations and/or prevent visual distraction from the movement of the club head and/or hands during the execution. As such, eye tracking may prove to be a worthwhile avenue for investigation into TFA. However, and as highlighted by prominent researchers within the field (Reinhoff, Baker, Fischer, Strauss \& Schorer, 2012; Wilson, Wood \& Vine, 2016), despite what appears to be conclusive data, we are still unaware of exactly why the eye is quiet during such executions.

\section{Nonvisual/Internal Focus Explanation}


To address this conundrum it may be important to consider whether what an athlete focuses on $i$ s the same as what they are looking at or indeed, thinking about. Study into target shooting by Loze, Collins and Holmes (2001) distinguishes between states of attention (as described above) and intention (see Wertheim, 1981). In this case, intention refers to a consciously controlled, centrally-driven feedforward mechanism of retrieval that is not dependent on the input of retinal information. Preshot electroencephalographic (EEG) alpha power reactivity during expert air pistol shooting demonstrated marked differences over the time course of the execution, showing higher power during the state of intention versus attention (Loze, Collins \& Shaw, 1999). This effect has been found to increase intraindividually before best shots in expert air pistol marksmen and elite archers (Landers, Han, Salazar, Petruzzello \& Kubitz, 1994; Salazar et al., 1990; Shaw, 1996). In addition, such patterns of neural activity have been observed on an interindividual level between sporting experts and non-athletes (Collins, Powell \& Davies, 1990; Cremades, 2002; Crews \& Landers, 1993; Del Percio et al., 2007; Hatfield, Landers \& Ray, 1984; Loze et al., 2001; Salazar et al., 1990). This is thought to be a sign of cortical inhibition during the period of stillness that occurs at the execution phase of a skilled motor act (Loze et al., 2001). Once the target is located and fixated on with an inevitably natural, but consistent, sway pattern, there is no longer a need to attend to the target; as it is not going to move (see Sheridan, 1991). Subsequently, a focus on controlling a smooth trigger pull, crucial for performance success (see also Bortoli et al., 2012), is initiated.

Notably, this explanation is in contrast to the constrained action hypothesis, which implies that athletes should be discouraged from focussing internally and instead advocates a universal benefit towards an external focus (Wulf, 2016). However, this argument and the studies used to derive it have recently been critiqued due to their lack of consideration toward motoric factors, such as the organisation, level and consistency of automaticity across movement components comprising the motor skill (cf. Carson \& Collins, 2016a). From this 
contemporary perspective, a "positive self-focus" (Carson \& Collins, 2016a, p. 10) toward the movement can serve to consciously activate the motor representation when thoughts relate to the entire movement (i.e., a holistic focus) or because an important, task-relevant component being focused on is highly-associated across others. Either way, these foci offer a beneficial action strategy to athletes for ensuring activation of the entire skill from long-term memory, especially when executing under novel or difficult conditions (cf. Christensen et al., 2016).

Accordingly, therefore, this nonvisual/internal focus activity may also be relevant for golfers when using the TFA method. A golfer might first attend to the target by fixating on the entry point of the hole (i.e., an external focus), then intend to initiate the putting action by focusing on an individually-optimal and familiar bodily thought (e.g., Maurer \& Munzert, 2013). Furthermore, and as a consequence of avoiding vision of the ball and club head, this may reduce distraction and potentially intrusive thoughts (e.g., "what's the club doing?") to permit even greater focus on the movement action. Therefore, in this scenario the more revealing measure might also be to employ EEG.

\section{Physio-Mechanical Explanation}

Finally, the employment of TFA may promote mechanical advantages during the putting stroke execution through a change in postural setup. As an exemplar of such difference within basketball, consider the relative effectiveness of free throwing using the conventional overarm, single handed, technique versus underarm, two handed, technique. When implementing the latter there is a clear mechanical advantage in that the movement and control of both limbs are more balanced, or in-phase (Haken, Kelso \& Bunz, 1985), thus predictably resulting in greater success (Venkadesan \& Mahadevan, 2017). Unfortunately, however, putting literature is predominated by kinematic studies of the putter rather than indepth (i.e., six degrees-of-freedom) analysis of the golfer to afford such insight (Delay, Nougier, Orliaguet \& Coello, 1997; Karlsen, Smith \& Nilsson, 2008). Might it be that 
tension in the neck and shoulder region when using TFA, in some way, makes the mechanics of the skeletal system different?

Based on findings from MacKenzie et al. (2011) showing a reduction in the variability of club head velocity at impact when using TFA, differential organisation of the skill by the central nervous system could be a possibility (Scholz \& Schöner, 1999). Adding to this, and exemplifying a distinct interactive effect across explanations, reductions in club head variability may also reflect differential organisation of the movement as a consciously initiated adaptation of the representation by the golfer (Carson, Collins \& Richards, 2014), or potentially as a result of the experimental conditions employed (Carson, Collins \& Richards, 2016). Indeed, this postural change, and associated components to the process, may allow the golfer to better estimate the correct amount of force to apply at impact, thus effecting the stroke speed variability (Cockerill, 1978; MacKenzie et al., 2011; Williams, Singer \& Frehlich, 2002). Presently, however, the precise underpinnings of how this may work remain outside the capability of this review. On the basis of these discussions, it follows that indepth kinematic and EMG tracking to determine the processes involved during the different phases of the putting stroke, such as impulse application and swing mechanics, would be well suited to explore this explanation (Sim \& Kim, 2010).

\section{Considerations for Future Research}

\section{Addressing What Has Been Missed}

Understanding what is going on. Human movement is the outcome of a plethora of biopsychosocial processes and it would be unsurprising to find similar interactions during TFA. This indicates, therefore, that future investigations into TFA must be able to account for such complexity but, for now, we simply do not know how or why TFA works, nor do we know what components or processes may or may not be associated with this phenomenon. As a case in point, alpha rhythms have not been investigated whilst putting using the TFA method. As such, there is a rationale for employing similar methods used in previous closed 
skills sport research to help understand how TFA might work (Gallicchio et al., 2017; Loze et al., 2001). Moreover, it is not what these processes will show us but what could be shown.

Moving forward, markers should be employed in research that reveals greater insight into how TFA might work. In addition, despite increasing literature surrounding the importance of vision, nonvision/internal focus and physio-mechanical control, there is no research regarding the efficiency and impact of TFA on putting performance when combining these control elements. Therefore, it is important that future research seeks to understand these mechanisms within representative environments and subsequently exploits this information within applied coaching practice. It would follow that identification and formative assessment of TFA as an appropriate aiming strategy following training interventions may reveal findings that can be applied in practice and utilised with confidence in a naturalistic, competitive and pressured environment. Furthermore, future research should consider the limitations surrounding ocular dominance and visual acuity prior to testing. As such, the evidence-base available is far from complete in explaining how TFA works.

The authors expect that any major change to a golfer's posture-eyes, head and neck position — during the stroke could, or should, cause degradation in performance. Therefore, a starting point for future studies would be to assess and interpret the putting skills of elite performers who have always putted using the BFA method and establish if the TFA method disrupts their performance. Furthermore, examining and investigating the golfer's physical characteristics including; height, vision acuity, postural and putting setup to determine the optimal position of the neck, head and eyes when engaging in the TFA method should prove productive. This information may then be used to assess lower skilled performers and for TFA training. Therefore, previous research would be further enhanced if future trials included elite amateur and professional golfers who have honed their putting skills. 
In this paper we suggest that current research into TFA is unfortunately characterised by several important inconsistencies and omissions. Consequently, this limits golf coaches' ability to know whether the method is effective, how it works and, therefore, who should use it, when and how it should be coached. More generally, we highlighted the need for research to be conducted as a linked chain whereby methodological revisions are data driven.

Accordingly, vision, nonvision/internal focus and physio-mechanical hypotheses were suggested that may provide impetus for an enhanced level of understanding. In conclusion, much work is needed toward TFA in the future and this should be systematic in its approach. At present, while anecdotal evidence of TFA's use by professional players and enthusiastic amateurs is interesting, that is all we really can say. Therefore, with great anticipation we await to gain a better understanding through future research studies, which may have a substantial impact within the applied setting. 


\section{References}

Abraham, A. \& Collins, D. (2011). Taking the next step: Ways forward for coaching science. Quest, 63, 366-384. doi:10.1080/00336297.2011.10483687

Aksamit, G. \& Husak, W. (1983). Feedback influences on the skill of putting. Perceptual and Motor Skills, 56, 19-22. doi:10.2466/pms.1983.56.1.19

Alpenfels, E., Christina, B. \& Heath, C. (2008). Instinct putting. New York: Penguin Group.

Bartlett, R. (2007). Introduction to sports biomechanics: Analysing human movement patterns ( $2^{\text {nd }}$ ed.). Abingdon: Routledge.

Beilock, S. L. \& Carr, T. H. (2001). On the fragility of skilled performance: What governs choking under pressure? Journal of Experimental Psychology: General, 130, 701725. doi:10.1037/0096-3445.130.4.701

Berkowitz, L. \& Donnerstein, E. (1982). External validity is more than skin deep: Some answers to criticisms of laboratory experiments. American Psychologist, 37, 245-257. doi:10.1037/0003-066X.37.3.245

Bertram, C. P. \& Guadagnoli, M. A. (2008). The effects of custom-fitted clubs versus "placebo" clubs on golf-swing characteristics. International journal of Sports Science \& Coaching, 3, S93-S98. doi:10.1260/174795408785024126

Blazevich, A. J. (2012). Sports biomechanics: The basics: Optimizing human performance ( $2^{\text {nd }}$ ed.). London: Bloomsbury.

Bortoli, L., Bertollo, M., Hanin, Y. \& Robazza, C. (2012). Striving for excellence: A multiaction plan intervention model for shooters. Psychology of Sport and Exercise, 13, 693-701. doi:10.1016/j.psychsport.2012.04.006

Bowen, R. T. (1968). Putting errors of beginning golfers using different points of aim. Research Quarterly. American Association for Health, Physical Education and Recreation, 39, 31-35. doi:10.1080/10671188.1968.10616526 
Carson, H. J. \& Collins, D. (2011). Refining and regaining skills in fixation/diversification stage performers: The Five-A Model. International Review of Sport and Exercise Psychology, 4, 146-167. doi:10.1080/1750984x.2011.613682

Carson, H. J. \& Collins, D. (2015). Tracking technical refinement in elite performers: The good, the better, and the ugly. International Journal of Golf Science, 4, 67-87. doi:10.1123/ijgs.2015-0003

Carson, H. J. \& Collins, D. (2016a). The fourth dimension: A motoric perspective on the anxiety-performance relationship. International Review of Sport and Exercise Psychology, 9, 1-21. doi:10.1080/1750984X.2015.1072231

Carson, H. J. \& Collins, D. (2016b). Implementing the Five-A Model of technical change: Key roles for the sport psychologist. Journal of Applied Sport Psychology, 28, 392409. doi:10.1080/10413200.2016.1162224

Carson, H. J., Collins, D. \& MacNamara, Á. (2013). Systems for technical refinement in experienced performers: The case from expert-level golf. International Journal of Golf Science, 2, 65-85. doi:10.1123/ijgs.2.1.65

Carson, H. J., Collins, D. \& Richards, J. (2014). Intra-individual movement variability during skill transitions: A useful marker? European Journal of Sport Science, 14, 327-336. doi:10.1080/17461391.2013.814714

Carson, H. J., Collins, D. \& Richards, J. (2016). Initiating technical refinements in high-level golfers: Evidence for contradictory procedures. European Journal of Sport Science, 16, 473-482. doi:10.1080/17461391.2015.1092586

Cheng, W.-N. K., Hardy, L. \& Markland, D. (2009). Toward a three-dimensional conceptualization of performance anxiety: Rationale and initial measurement development. Psychology of Sport and Exercise, 10, 271-278. doi:10.1016/j.psychsport.2008.08.001 
Christensen, W., Sutton, J. \& McIlwain, D. (2016). Cognition in skilled action: Meshed control and the varieties of skill experience. Mind and Language, 31, 37-66. doi:10.1111/mila.12094

Christina, R. W. (1987). Motor learning: Future lines of research. In M. J. Safrit \& H. M. Eckert (Eds.), The cutting edge in physical education and exercise science research (pp. 26-41). Champaign, IL: Human Kinetics.

Cockerill, I. M. (1978). Visual control in golf putting. In C. H. Nadeau, W. R. Halliwell, K. M. Newell, \& G. C. Roberts (Eds.), Psychology of motor behaviour and sport (pp. 377-384). Champaign, IL: Human Kinetics.

Collins, D., Carson, H. J. \& Cruickshank, A. (2015). Blaming Bill Gates AGAIN! Misuse, overuse and misunderstanding of performance data in sport. Sport, Education and Society, 20, 1088-1099. doi:10.1080/13573322.2015.1053803

Collins, D. \& Kamin, S. (2012). The performance coach. In S. M. Murphy (Ed.), The Oxford handbook of sport and performance psychology (pp. 692-706). New York: Oxford University Press.

Collins, D., Powell, G. \& Davies, I. (1990). An electroencephalographic study of hemispheric processing patterns during karate performance. Journal of Sport and Exercise Psychology, 12, 223-234. doi:10.1123/jsep.12.3.223

Cremades, J. G. (2002). The effects of imagery perspective as a function of skill level on alpha activity. International Journal of Psychophysiology, 43, 261-271. doi:10.1016/S0167-8760(01)00186-6

Crews, D. J. \& Landers, D. M. (1993). Electroencephalographic measures of attentional patterns prior to the golf putt. Medicine and Science in Sports and Exercise, 25, 116126. doi:10.1249/00005768-199301000-00016

Crossman, E. R. F. W. (1959). A theory of the acquisition of speed-skill. Ergonomics, 2, 153166. doi:10.1080/00140135908930419 
Del Percio, C., Marzano, N., Tilgher, S., Fiore, A., Di Ciolo, E., Aschieri, P., . . Eusebi, F. (2007). Pre-stimulus alpha rhythms are correlated with post-stimulus sensorimotor performance in athletes and non-athletes: A high-resolution EEG study. Clinical Neurophysiology, 118, 1711-1720. doi:10.1016/j.clinph.2007.04.029

Delay, D., Nougier, V., Orliaguet, J.-P. \& Coello, Y. (1997). Movement control in golf putting. Human Movement Science, 16, 597-619

Drane, P., Duffy, M., Fournier, J., Sherwood, J. \& Breed, M. (2014). The behavior of golf ball putting on artificial turf. Procedia Engineering, 72, 599-604. doi:10.1016/j.proeng.2014.06.107

Farnsworth, C. L. (1997). See it \& sink it. Mastering putting performance through peak visual performance. London: HarperCollins. .

Fischman, M. G. (2015). On the continuing problem of inappropriate learning measures: Comment on Wulf et al. (2014) and Wulf et al. (2015). Human Movement Science, 42, 225-231. doi:10.1016/j.humov.2015.05.011

Gallicchio, G., Cooke, A. \& Ring, C. (2017). Practice makes efficient: Cortical alpha oscillations are associated with improved golf putting performance. Sport, Exercise, and Performance Psychology, 6, 89-102. doi:10.1037/spy0000077

Goginsky, A. M. \& Collins, D. (1996). Research design and mental practice. Journal of Sports Sciences, 14, 381-392. doi:10.1080/02640419608727725

Gonzalez, D. A., Kegel, S., Ishikura, T. \& Lee, T. (2012). Effects of vision on head-putter coordination in golf. Motor Control, 16, 371-385. doi:10.1123/mcj.16.3.371

Gott, E. \& McGown, C. (1988). Effects of a combination of stances and points of aim on putting accuracy. Perceptual and Motor Skills, 66, 1399-1143.

doi:10.2466/pms.1988.66.1.139 
Haken, H., Kelso, J. A. S. \& Bunz, H. (1985). A theoretical model of phase transitions in human hand movements. Biological Cybernetics, 51, 347-356. doi:10.1007/bf00336922

Hasegawa, Y., Fujii, K., Miura, A. \& Yamamoto, Y. (2017). Resolution of low-velocity control in golf putting differentiates professionals from amateurs. Journal of Sports Sciences, 35, 1239-1246. doi:10.1080/02640414.2016.1218037

Hatfield, B. D., Haufler, A. J., Hung, T. M. \& Spalding, T. W. (2004). Electroencephalographic studies of skilled psychomotor performance. Journal of Clinical Neurophysiology, 21, 144-156. doi:10.1097/00004691-200405000-00003

Hatfield, B. D., Landers, D. M. \& Ray, W. J. (1984). Cognitive processes during self-paced motor performance: An electroencephalographic profile of skilled marksmen. Journal of Sport Psychology, 6, 42-59. doi:10.1123/jsp.6.1.42

Karlsen, J., Smith, G. \& Nilsson, J. (2008). The stroke has only a minor influence on direction consistency in golf putting among elite players. Journal of Sports Sciences, 26, $243-$ 250. doi:10.1080/02640410701530902

Keogh, J. W. L. \& Hume, P. A. (2012). Evidence for biomechanics and motor learning research improving golf performance. Sports Biomechanics, 11, 288-309. doi:10.1080/14763141.2012.671354

Landers, D. M., Han, M., Salazar, W., Petruzzello, S. J. \& Kubitz, K. A. (1994). Effects of learning on electroencephalographic and electrocardiographic patterns in novice archers. International Journal of Sport Psychology, 25, 313-330

Lee, T. D., Ishikura, T., Kegel, S., Gonzalez, D. \& Passmore, S. (2008). Head-putter coordination patterns in expert and less skilled golfers. Journal of Motor Behavior, 40, 267-272. doi:10.3200/JMBR.40.4.267-272 
Loze, G. M., Collins, D. \& Holmes, P. S. (2001). Pre-shot EEG alpha-power reactivity during expert air-pistol shooting: A comparison of best and worst shots. Journal of Sports Sciences, 19, 727-733. doi:10.1080/02640410152475856

Loze, G. M., Collins, D. \& Shaw, J. C. (1999). EEG alpha rhythm, intention and oculomotor control. International Journal of Psychophysiology, 33, 163-167. doi:10.1016/S01678760(99)00024-0

MacKenzie, S. J., Foley, S. M. \& Adamczyk, A. P. (2011). Visually focusing on the far versus the near target during the putting stroke. Journal of Sports Sciences, 29, 12431251. doi:10.1080/02640414.2011.591418

Mann, D. T., Williams, A. M., Ward, P. \& Janelle, C. M. (2007). Perceptual-cognitive expertise in sport: A meta-analysis. Journal of Sport and Exercise Psychology, 29, 457-478. doi:10.1123/jsep.29.4.457

Masters, R. S. W. (1992). Knowledge, knerves and know-how: The role of explicit versus implicit knowledge in the breakdown of a complex motor skill under pressure. British Journal of Psychology, 83, 343-358. doi:10.1111/j.2044-8295.1992.tb02446.x

Maurer, H. \& Munzert, J. (2013). Influence of attentional focus on skilled motor performance: Performance decrement under unfamiliar focus conditions. Human Movement Science, 32, 730-740. doi:10.1016/j.humov.2013.02.001

McHardy, A., Pollard, H. \& Bayley, G. (2006). A comparison of the modern and classic golf swing: A clinician's perspective. South African Journal of Sports Medicine, 18, 8092. doi:10.17159/2078-516X/2006/v18i3a239

Meister, D. W., Ladd, A. L., Butler, E. E., Zhao, B., Rogers, A. P., Ray, C. J. \& Rose, J. (2011). Rotational biomechanics of the elite golf swing: Benchmarks for amateurs. Journal of Applied Biomechanics, 27, 242-251. doi:10.1123/jab.27.3.242 
Monk, S. A., Davis, C. L., Strangwood, M. \& Otto, S. R. (2004). The effect of friction coefficient and surface properties on spin generation and launch angle in golf wedges. Engineering of Sport, 5, 230-237

Moore, L. J., Vine, S. J., Cooke, A., Ring, C. \& Wilson, M. R. (2012). Quiet eye training expedites motor learning and aids performance under heightened anxiety: The roles of response programming and external attention. Psychophysiology, 49, 1005-1015. doi:10.1111/j.1469-8986.2012.01379.x

Newell, K. M., Liu, Y.-T. \& Mayer-Kress, G. (2001). Time scales in motor learning and development. Psychological Review, 108, 57-82. doi:10.1037/0033-295X.108.1.57

Nieuwenhuys, A. \& Oudejans, R. R. D. (2012). Anxiety and perceptual-motor performance: Toward an integrated model of concepts, mechanisms, and processes. Psychological Research, 76, 747-759. doi:10.1007/s00426-011-0384-x

Reinhoff, R., Baker, J., Fischer, L., Strauss, B. \& Schorer, J. (2012). Field of vision influences sensory-motor control of skilled and less-skilled dart players. Journal of Sports Science and Medicine, 11, 542-550

Robertson, S., Gupta, S., Kremer, P. \& Burnett, A. F. (2015). Development and measurement properties of a putting skill test for high-level golf. European Journal of Sport Science, 15, 125-133. doi:10.1080/17461391.2014.932014

Rodgers, W., Reade, I. \& Hall, C. (2007). Factors that influence coaches' use of sound coaching practices. International journal of Sports Science \& Coaching, 155-170. doi:10.1260/174795407781394284

Rose, D. J. (1997). A multilevel approach to the study of motor control and learning. Needham Heights, MA: Allyn \& Bacon.

Salazar, W., Landers, D. M., Petruzzello, S. J., Han, M., Crews, D. J. \& Kubitz, K. A. (1990). Hemispheric asymmetry, cardiac response, and performance in elite archers. Research 
Quarterly for Exercise and Sport, 61, 351-359.

doi:10.1080/02701367.1990.10607499

Schmidt, R. A. (1975). A schema theory of discrete motor skill learning. Psychological Review, 82, 225-260

Scholz, J. P. \& Schöner, G. (1999). The uncontrolled manifold concept: Identifying control variables for a functional task. Experimental Brain Research, 126, 289-306. doi:10.1007/s002210050738

Shaw, J. C. (1996). Intention as a component of the alpha-rhythm response to mental activity. International Journal of Psychophysiology, 24, 7-23. doi:10.1016/S01678760(96)00052-9

Sheridan, M. R. (1991). Initiation and execution of movement. A unified approach. In J. Requin \& G. E. Stelmach (Eds.), Tutorials in motor neuroscience (pp. 313-332). Dordrecht: Kluwer Academic Publishers.

Sim, M. \& Kim, J.-U. (2010). Differences between experts and novices in kinematics and accuracy of golf putting. Human Movement Science, 29, 932-946. doi:10.1016/j.humov.2010.07.014

Smith, A., Roberts, J., Wallace, E., Pui, W. K., Forrester, S., MacKenzie, S. \& Robertson, S. (2015). Golf coaches' perceptions of key technical swing parameters compared to biomechanical literature. International journal of Sports Science \& Coaching, 10, 739-755. doi:10.1260/1747-9541.10.4.739

Steinberg, G. M., Frehlich, S. G. \& Tennant, K. L. (1995). Dextrality and eye position in putting performance. Perceptual \& Motor Skills, 80, 635-640.

doi:10.2466/pms.1995.80.2.635

Swash. (2016). Putter custom fitting. Retrieved from http://www.haroldswashputting.co.uk/c-groove/custom-fitting.html 
Taylor, J. A. \& Shaw, D. F. (2002). The effects of outcome imagery on golf-putting performance. Journal of Sports Sciences, 20, 607-613. doi:10.1080/026404102320183167

Toner, J. \& Moran, A. (2015). Enhancing performance proficiency at the expert level: Considering the role of 'somaesthetic awareness'. Psychology of Sport and Exercise, 16, 110-117. doi:10.1016/j.psychsport.2014.07.006

Venkadesan, M. \& Mahadevan, L. (2017). Optimal strategies for throwing accurately. Royal Society Open Science, 4, 170136. doi:10.1098/rsos.170136

Vickers, J. N. (2012). Neuroscience of the quiet eye in golf putting. International Journal of Golf Science, 1, 2-9. doi:10.1123/ijgs.1.1.2

Vickers, J. N. (2016). Origins and current issues in Quiet Eye research. Current Issues in Sport Science, 1, 101. doi:10.15203/CISS_2016.101

Wannebo, M. \& Reeve, T. G. (1984). Effects of skill level and sensory information on golf putting. Perceptual and Motor Skills, 58, 611-613. doi:10.2466/pms.1984.58.2.611

Wertheim, A. H. (1981). Occipital alpha activity as a measure of retinal involvement in oculomotor control. Psychophysiology, 18, 432-439. doi:10.1111/j.14698986.1981.tb02476.x

Williams, A. M., Singer, R. N. \& Frehlich, S. G. (2002). Quiet eye duration, expertise, and task complexity in near and far aiming tasks. Journal of Motor Behavior, 34, 197-207. doi:10.1080/00222890209601941

Wilson, M. R. \& Pearcy, R. C. (2009). Visuomotor control of straight and breaking golf putts. Perceptual and Motor Skills, 109, 555-562. doi:10.2466/pms.109.2.555-562

Wilson, M. R., Wood, G. \& Vine, S. J. (2016). Say it quietly, but we still do not know how Quiet Eye training works - comment on Vickers. Current Issues in Sport Science, 1, 117. doi:10.15203/CISS_2016.117 
Wulf, G. (2013). Attentional focus and motor learning: A review of 15 years. International Review of Sport and Exercise Psychology, 6, 77-104. doi:10.1080/1750984x.2012.723728

Wulf, G. (2016). An external focus of attention is a conditio sine qua non for athletes: A response to Carson, Collins, and Toner (2015). Journal of Sports Sciences, 34, 12931295. doi:10.1080/02640414.2015.1136746 
Table 1. Overview of Research to date Investigating Target Focused Aiming in Golf.

\begin{tabular}{|c|c|c|c|c|c|c|c|}
\hline Study & $\begin{array}{l}\text { Purpose of } \\
\text { Study }\end{array}$ & $\begin{array}{c}\text { Theoretical } \\
\text { Perspective } \\
\text { Adopted }\end{array}$ & $\begin{array}{c}\text { Participant } \\
\text { Characteristics } \\
\text { and Number }(N)\end{array}$ & $\begin{array}{c}\text { Context } \\
\text { Tested } \\
\text { Under } \\
\end{array}$ & $\begin{array}{c}\text { Type of } \\
\text { Manipulation(s) }\end{array}$ & Conclusions & $\begin{array}{c}\text { Citing } \\
\text { Research }\end{array}$ \\
\hline $\begin{array}{l}\text { Bowen } \\
(1968)\end{array}$ & $\begin{array}{l}\text { To determine if } \\
\text { beginner golfers } \\
\text { made } \\
\text { characteristic } \\
\text { errors over } \\
\text { various putting } \\
\text { terrains and to } \\
\text { discover if } \\
\text { looking at the } \\
\text { ball vs. at the } \\
\text { hole while } \\
\text { putting would } \\
\text { increase } \\
\text { accuracy. }\end{array}$ & $\begin{array}{l}\text { No } \\
\text { mechanistic } \\
\text { explanation } \\
\text { provided; } \\
\text { however, } \\
\text { tentatively } \\
\text { cognitive } \\
\text { orientation } \\
\text { towards the } \\
\text { results. }\end{array}$ & $\begin{array}{l}\text { Beginner male } \\
\text { college students } \\
(N=100) \text {. } \\
\text { Eight were left- } \\
\text { handed and } 92 \\
\text { right-handed. } \\
\text { A standardised } \\
\text { putter was used. }\end{array}$ & $\begin{array}{l}\text { Outdoor } \\
\text { synthetic } \\
\text { level and } \\
\text { angled carpet } \\
\text { surface (hair } \\
\text { and jute). }\end{array}$ & $\begin{array}{l}\text { BFA vs. TFA. } \\
300 \text { putts }-25 \\
\text { from } 15 \mathrm{ft}, 25 \mathrm{ft} \text { and } \\
35 \mathrm{ft} \text { on a level } \\
\text { surface and } \\
\text { repeated on an } \\
\text { uphill-sidehill } \\
\text { surface, a } \\
\text { downhill-sidehill } \\
\text { surface and an } \\
\text { undulating surface. }\end{array}$ & $\begin{array}{l}\text { No significant } \\
\text { difference in } \\
\text { performance } \\
\text { between BFA and } \\
\text { TFA groups for } \\
\text { any condition } \\
\text { (slope or } \\
\text { distance). } \\
\text { Success in putting } \\
\text { distance and } \\
\text { direction is not } \\
\text { related to gaze } \\
\text { direction. } \\
\text { Emphasised } \\
\text { instruction on } \\
\text { distance control } \\
\text { and the influence } \\
\text { of slope is } \\
\text { required. }\end{array}$ & None \\
\hline $\begin{array}{l}\text { Cockerill } \\
\text { (1978) }\end{array}$ & $\begin{array}{l}\text { To determine } \\
\text { how effort } \\
\text { control in } \\
\text { putting might be } \\
\text { facilitated } \\
\text { among low- }\end{array}$ & $\begin{array}{l}\text { Cognitive } \\
\text { but with } \\
\text { minimal } \\
\text { mechanistic } \\
\text { discussion. }\end{array}$ & $\begin{array}{l}\text { Right-handed, } \\
\text { male low- } \\
\text { handicap golfers } \\
\text { ( } n=20 ;<6 \\
\text { handicap; aged } \\
22-42 \text { years) and } \\
\text { non-golfers ( } n=\end{array}$ & $\begin{array}{l}\text { Laboratory, } \\
0.1 \mathrm{~m} \text { high } \\
\text { synthetic } \\
\text { putting mat } \\
\text { with standard } \\
\text { hole cut. }\end{array}$ & $\begin{array}{l}\text { BFA vs. TFA. } \\
\text { Putting distances } \\
\text { of } 1 \mathrm{~m} \text { and } 2 \mathrm{~m} \text {. } \\
\text { Vision restricted } \\
\text { by a triangular } \\
\text { blinker attached to }\end{array}$ & $\begin{array}{l}\text { Putting distance } \\
\text { was a significant } \\
\text { source of } \\
\text { performance } \\
\text { variation. Non- } \\
\text { golfers mainly } \\
\text { suffered from }\end{array}$ & $\begin{array}{l}\text { Bowen } \\
\text { (1968) }\end{array}$ \\
\hline
\end{tabular}


handicap golfers and non-golfers.

$\begin{array}{ll}\text { Aksamit \& } & \text { To determine } \\ \text { Husak } & \text { the influence of } \\ \text { (1983) } & \text { two forms of } \\ & \text { visual control } \\ & \text { and one } \\ & \text { kinesthetic } \\ & \text { technique on } \\ & \text { accuracy of } \\ \text { putting }\end{array}$

20, aged 20-38

years). A

standardised

centre shaft putter

and Dunlop 65

ball were used.

\section{Cognitive}

\section{Right-handed,}

female, non-golfer college students

$(N=27)$.

(atural

putting green

(30.5ft $x$

40.5ft).

Standardised

putter and ball

used. the left side of the head for BFA and right side for TFA.

Each participant

executed 25 putts

from each

distance.

BFA vs. TFA vs

no vision (using

blackened

goggles).

Participants

randomly assigned into each of three

groups.

5 putts from $5 \mathrm{ft}$, $10 \mathrm{ft}$ and $15 \mathrm{ft}$ per group. directional errors to the right of the hole using TFA. For TFA to be effective in experienced golfers, it was suggested that the golfer would benefit from early exposure to using the TFA method.

No significant difference across the three

conditions. As

distance

decreased the groups mean errors decreased.

No vision during early skill

acquisition may be beneficial by forcing attention toward important movements and preventing informationprocessing overload from 


$\begin{array}{ll}\text { Wannebo \& } & \begin{array}{l}\text { To examine the } \\ \text { Reeve }\end{array} \\ \text { role of sensory } \\ \text { feedback and } \\ \text { skill level in } \\ \text { golf putting } \\ \text { performance. }\end{array}$

$\begin{array}{ll}\begin{array}{l}\text { Gott \& } \\ \text { McGown }\end{array} & \begin{array}{l}\text { To determine } \\ \text { the effects of } \\ \text { (1988) }\end{array} \\ & \begin{array}{l}\text { two putting } \\ \text { stances } \\ \text { (conventional }\end{array} \\ & \text { vs. side-saddle) } \\ & \text { and two points } \\ & \text { of aim (ball vs. }\end{array}$

\section{No}

theoretical

perspective adopted.
Highly skilled, male golf students (minimum 3 years' experience; $n=11)$ and lowskilled golfers (< 6 months' experience; $n=$ 11).

Participants used their own putters or the one supplied.

5 range balls were used (nonconforming for competitive play).

$\begin{array}{ll}\text { Cognitive } & 12 \text { male and } 4 \\ \text { but with } & \text { female right- } \\ \text { minimal } & \text { handed students } \\ \text { mechanistic } & \begin{array}{l}\text { enrolled in } \\ \text { explanation. } \\ \text { beginner } \\ \text { (inexperienced) } \\ \text { golf class. }\end{array}\end{array}$

Laboratory, synthetic level putting surface (10ft $\times 25 \mathrm{ft}$ ) with hole.

Natural putting green ( 40ft $x$ $35 \mathrm{ft})$.

Laboratory,
synthetic
level putting
surface (10ft
$\times 25 \mathrm{ft})$ with
hole.

irrelevant environmental information.

BFA vs. no visual BFA was

Aksamit \& cues (blindfolded) significantly more vs. irrelevant visual cues.

5 straight putts from $5 \mathrm{ft}$ and $15 \mathrm{ft}$ in each condition.

Offset marker (the irrelevant visual cue) was placed 58in. from the hole and marked with white tape as an ' $\mathrm{X}$ '.

accurate

Husak

compared with

(1983);

the other two

Cockerill,

conditions. There

was no significant

difference

between no visual

and irrelevant

visual cues.

Relevant visual

cues are important for accurate putting.

Conventional
stance vs. side-
saddle using BFA
and TFA
combinations (i.e.,
4 manipulations)
from 5ft and 15ft.

Bowen

differences at any (1968);

distance between Cockerill point of aim or (1978) stance. 
hole) on putting

accuracy.
Participants were randomly divided into four genderbalanced groups.
Practice: 60 putts from each distance 1 day per week on weeks $1,3,5$ and 7.

Testing: Same as practice but in weeks 2, 4, 6 and 8.

Incentive rewards each week for most number of putts holed.

$\begin{array}{ll}\text { Alpenfels, } & \text { The intent of } \\ \text { Christina \& } & \text { this book } \\ \text { Heath } & \text { "Instinct } \\ \text { (2008) } & \text { Putting" (IP) is } \\ & \text { to impart a clear } \\ & \text { understanding } \\ & \text { of IP and act as } \\ & \text { a guide to } \\ & \text { adopting IP for } \\ & \text { your own game } \\ & \text { through a } \\ & \text { program of } \\ & \text { practice drills } \\ & \text { and exercises }\end{array}$

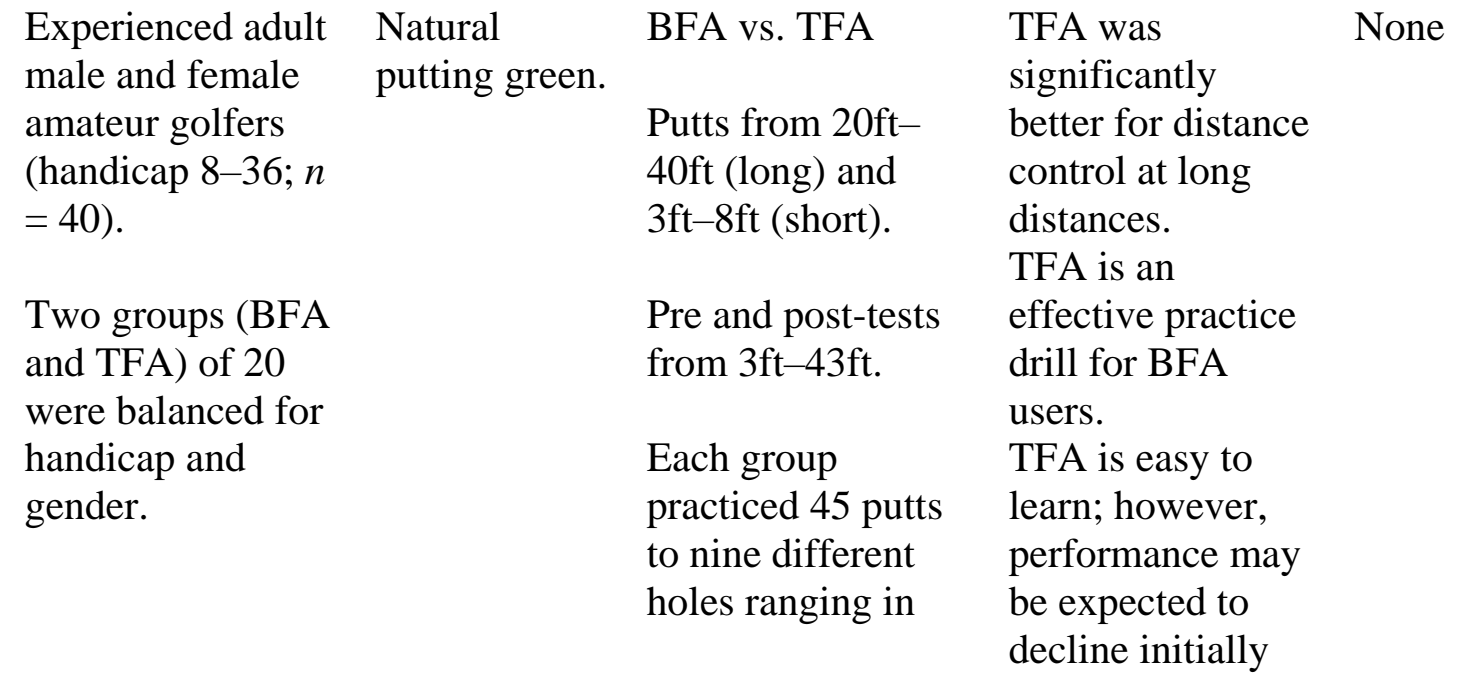


distance from $5 \mathrm{ft}-$ $45 \mathrm{ft}$.

$\begin{array}{ll}\text { MacKenzie, } & \text { To evaluate } \\ \text { Foley \& } & \text { BFA vs. TFA, } \\ \text { Adamczyk } & \text { following a } \\ \text { (2011) } & \begin{array}{l}\text { series of } \\ \text { practice } \\ \text { sessions. }\end{array}\end{array}$

Cognitive

Thirty-one male golfers (handicap $18.7 \pm 10.4 ; M$ age $=22.3$ years \pm $4.1)$.

11 left- and 20 right-handed.

All putts were executed with a standardised Nike Unitized Retro putter. Balls

(Callaway Touri) were marked with a straight line for aiming purposes.

Participants were provided with a correctly orientated aim line to improve internal validity and affect
Laboratory, BFA vs. TFA. Post-test results synthetic putting surface $7 \mathrm{~m} \times$ $5 \mathrm{~m}$. Green speed stimp ( 11.5ft).

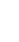

Pre-test-4 week
practice (BFA or
TFA)-post-test
(using both TFA
and BFA at $1.22 \mathrm{~m}$
and $4 \mathrm{~m}$ ).

Straight putts.

\section{before \\ improvements are evidenced.}

\begin{tabular}{|c|c|}
\hline $\begin{array}{l}\text { Post-test results } \\
\text { showed TFA } \\
\text { practice group } \\
\text { significantly } \\
\text { reduced } \\
\text { variability in } \\
\text { putter speed. } \\
\text { TFA practice did } \\
\text { not affect the } \\
\text { quality of impact } \\
\text { of putter-ball }\end{array}$ & $\begin{array}{l}\text { Aksamit \& } \\
\text { Husak } \\
\text { (1983); } \\
\text { Bowen } \\
\text { (1968); } \\
\text { Cockerill, } \\
\text { (1978); Gott } \\
\text { \& McGown } \\
\text { (1988); } \\
\text { Wannebo \& } \\
\text { Reeve (1984) }\end{array}$ \\
\hline
\end{tabular}

Four weeks of practice using TFA method resulted in improvements in putter speed consistency when tested using TFA but this finding also remained when returning back to BFA. 
generalizability of results.

\section{Participants were} divided into two matched groups based on their pretest putting

performance.

$\begin{array}{lll}\text { Gonzalez, } & \text { To examine } & \text { Cognitive } \\ \text { Kegel, } & \text { effects of vision } & \\ \text { Ishikura \& } & \begin{array}{l}\text { on head-putter } \\ \text { coupling }\end{array} & \\ \text { Lee (2012) } & \text { coung }\end{array}$

\section{Twelve right- \\ handed \\ participants (3 \\ male, 9 female) \\ with less than 3 \\ years of golf \\ experience.}

All used Titleist

NXT golf balls

and a Ping Anser

Putter.

\begin{tabular}{|c|c|c|c|}
\hline $\begin{array}{l}\text { Laboratory } \\
\text { synthetic } \\
\text { carpet } \\
(632 \mathrm{~cm} \times \\
183 \mathrm{~cm}) \text { with } \\
\text { a speed } \\
\text { reading of } 13 \\
\text { on the stimp } \\
\text { metre. Putts } \\
\text { were to two } \\
\text { golf hole } \\
\text { sized targets } \\
\text { located at } \\
\text { distances of } \\
3 \mathrm{~m} \text { and } 5 \mathrm{~m} .\end{array}$ & $\begin{array}{l}\text { Each participant } \\
\text { executed } 3 \mathrm{~m} \text { and } \\
5 \mathrm{~m} \text { straight putts } \\
\text { under four } \\
\text { conditions (Full } \\
\text { Vision, No Vision, } \\
\text { BFA-Restricted } \\
\text { and TFA). } \\
\text { Opaque sheet used } \\
\text { to remove vision } \\
\text { of the ball and } \\
\text { immediate } \\
\text { surrounding area. }\end{array}$ & $\begin{array}{l}\text { Visual strategies } \\
\text { play a role in the } \\
\text { coordination of } \\
\text { head and putter } \\
\text { motions and } \\
\text { outcome of putts. } \\
\text { Full Vision } \\
\text { resulted in } \\
\text { considerable head } \\
\text { movement } \\
\text { throughout the } \\
\text { putt. }\end{array}$ & $\begin{array}{l}\text { Alpenfels, } \\
\text { Christina, \& } \\
\text { Heath (2008) }\end{array}$ \\
\hline
\end{tabular}

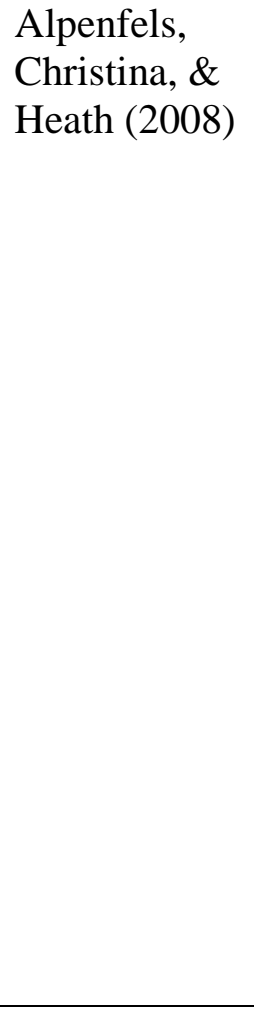


entire ball and

putter head as it struck the ball by the golfer.

10 practice putts permitted in each condition.

The eight experimental conditions were run in four blocks of sixteen putts, four putts in each condition (two putts per target distance). and had the largest effect on head-putter coordination pattern but lead to a decrease in performance outcome.

BFA-Restricted

like TFA was successful by decoupling the degrading effects of an isodirectional coordination pattern

BFA-Restricted being the optimal condition for this experiment. 